\title{
PENGARUH BENTUK GALVANIS SEBAGAI SERAT PADA BETON DITINJAU DARI KUAT TARIK BELAH DAN KUAT LENTUR BETON
}

\author{
Karmila Achmad (1), Sunarno(2) \\ (1)milabpp@yahoo.co.id \\ (1)(2)Politeknik Negeri Balikpapan \\ Ringkasan
}

\begin{abstract}
Serat dalam beton berfungsi mencegah retak-retak sehingga menjadikan beton lebih kuat daripada beton tanpa serat. Kawat galvanis banyak digunakan karena murah, mudah dibentuk dan mudah perawatannya. Tujuan penelitian untuk mendapatkan material serat buatan yang relatif murah dan mampu meningkatkan kekuatan beton secara optimal ditinjau dari kuat tarik dan kuat lentur. Material agregat halus yang digunakan dalam penelitian ini adalah material lokal pasir Samboja. Jenis Serat yang digunakan berupa serat buatan kawat galvanis berbentuk linting, spiral dan crimped. Hasil penelitian menunjukan bahwa benda uji BC1 (Crimped ob $1 \mathrm{~cm}$ ) memiliki kekuatan tarik terbesar dan L5 (Linting 5) memiliki kekuatan lentur terbesar dibandingkan benda uji lainnya. Besarnya kuat tarik yaitu 10,44 MPa dan kuat lentur sebesar 7,03 MPa.
\end{abstract}

Kata Kunci : Beton Serat, Kawat Galvanis, Kuat Lentur, Kuat Tarik

\section{PENDAHULUAN}

\section{Beton Serat}

Beton serat adalah bahan komposit yang terdiri dari beton biasa dan bahan lain yang berupa serat. Serat dalam beton ini berfungsi mencegah retak-retak sehingga menjadikan beton lebih kuat daripada beton biasa. Bahan serat dapat berupa serat asbestos, serat plastik (poly-propyline), atau potongan kawat baja, serat tumbuh-tumbuhan seperti rami, sabut kelapa, bambu, dan ijuk.

Pembuatan beton serat adalah dengan menambahkan serat kedalam campuran beton, yang betujuan untuk meningkatkan kekuatan beton agar dan mampu menunda kehancuran beton. Banyak sifat-sifat beton yang dapat diperbaiki dengan penambahan serat seperti: meningkatnya daktilitas, ketahanan impact, meningkatnya kuat tarik dan lentur, ketahanan terhadap fatigue, ketahanan terhadap pengaruh susutan, ketahanan abrasi, ketahanan terhadap pecahan atau fragmentasi, ketahanan terhadap pengelupasan.

Kawat galvanis merupakan material baja dan besi yang diberi pelapis seng untuk mencegah korosi. Seng merupakan logam yang relatif tahan karat, seng bekerja sebagai proteksi katodik yang melindungi baja. Kawat galvanis banyak digunakan karena murah dan mudah perawatannya. Kawat galvanis ini dapat dimanfaatkan pada pembuatan beton serat yang berfungsi untu menunda keruntuhan beton akibat beban yang bekerja.

Edy Purwanto, 2011 meneliti besar kemampuan beton ringan berserat kawat galvanis untuk menahan gaya lentur pada balok beton tanpa tulangan. Dengan variasi serat $0 \% ; 0,3 \% ; 0,75 \% ; 1 \%$ nilai kuat lentur yang diperoleh berturut-turut adalah 2,76 $\mathrm{MPa}$; 3,17 MPa; 3,78 $\mathrm{MPa}$ dan 4,37 $\mathrm{MPa}$. Peningkatan kuat tekan terbesar terjadi pada variasi serat $1 \%$ yaitu $58,32 \%$. Penambahan persentase serat dalam campuran beton mampu meningkatkan kuat lentur dan kuat tekan beton.

Basuki, 2013 meneliti besar kuat lentur pada balok beton bertulang dengan penambahan kawat galvanis dengan variasi diameter kawat $1,02 \mathrm{~mm} ; 1,29 \mathrm{~mm}$ dan $1,63 \mathrm{~mm}$. Dari hasil penelitian disimpulkan bahwa kawat galvanis mampu menigkatkan kuat lentur pada balok beton bertulang dengan peningkatan kuat lentur sebesar $21,93 \%, 51,18 \%$ dan $70,52 \%$ masing-masin untuk diameter kawat galvanis $1,02 \mathrm{~mm}$; $1,29 \mathrm{~mm}$ dan $1,63 \mathrm{~mm}$.

Ahmad Saifuddin, 2015: semakin besar aspek rasio penambahan serat baja akan memberikan kinerja kuat tarik belah yang lebih baik. Untuk dosis serat $20 \mathrm{~kg} / \mathrm{m}^{3}, 40$ $\mathrm{kg} / \mathrm{m}^{3}, 60 \mathrm{~kg} / \mathrm{m}^{3}, 80 \mathrm{~kg} / \mathrm{m}^{3}$, diperoleh kuat tarik belah terbesar adalah $44,62 \%$ untuk dosis serat $80 \mathrm{~kg} / \mathrm{m}^{3}$. Penelitian yang dilakukan oleh Abdul Aziz, 2016 
menghasilkan bahwa kuat tarik belah beton meningkat dengan penambahan dramix steel fiber, dengan peningkatan kuat tarik belah rata-rata adalah $41,4 \%$ untuk mutu beton 20 MPa dan 24,48\% untuk mutu beton $40 \mathrm{Mpa}$.

\section{Tujuan}

Tujuan penelitian ini adalah untuk mendapatkan material serat buatan yang relatif murah dan mampu meningkatkan kekuatan beton secara optimal baik ditinjau dari segi kuat tekan, kuat tarik dan kuat lentur.

\section{METODE PENELITIAN}

\section{Benda Uji}

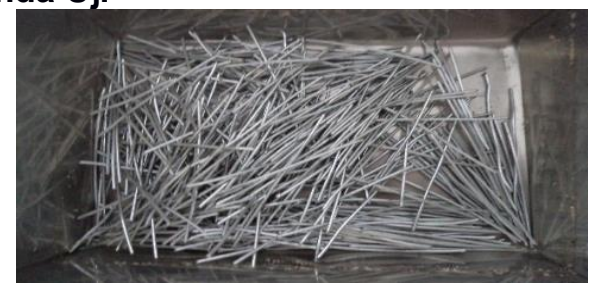

(a)

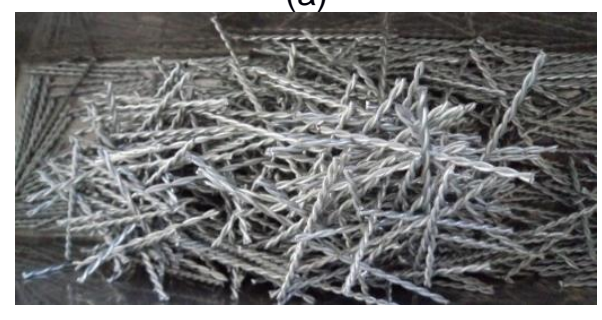

(b)

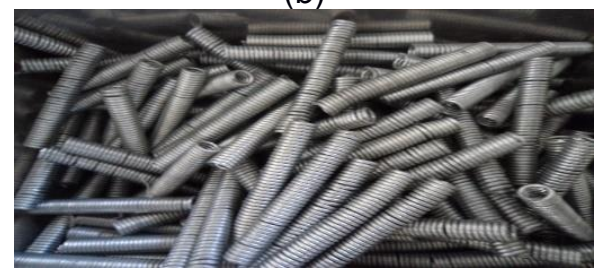

(c)

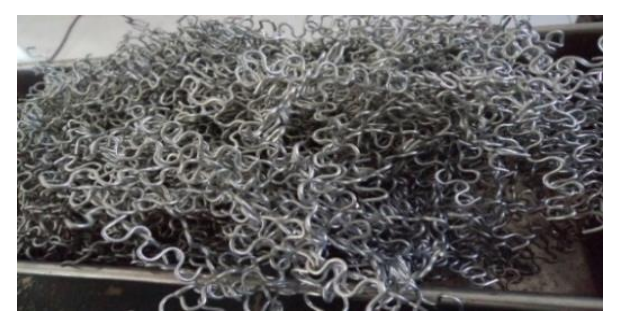

(d)

Gambar 1. Kawat Galvanis: (a) Tanpa model, (b) Model Linting, (c) Model Spiral dan (d) Model Crimped

Material agregat yang digunakan dalam penelitian ini adalah materil lokal pasir Samboja. Mutu beton 20MPa dan mutu baja tulangan $240 \mathrm{MPa}$. Jenis Serat yag digunakan berupa serat buatan dari kawat galvanis sepanjang $5 \mathrm{~cm}$, kawat galvanis yang dibentuk dengan model Linting, Spiral dan Crimped. Keseluruhan benda uji akan dibandingkan dengan beton tanpa galvanis dan beton dengan penambahan kawat galvanis tanpa model. Selain pola galvanis variasi benda uji juga berupa variasi diameter KAWAT GALVANIS YANG DIGUNAKAN, YAITU: $\Phi$ 0,6 cm; $\phi 1 \mathrm{~cm}$; क 1,6 cm; dan $\phi$ $2 \mathrm{~cm}$ baik untuk model linting, spiral maupun model crimped. Serat yang digunakan seperti pada gambar 1 .

Tabel 1. Benda Uji Penelitian

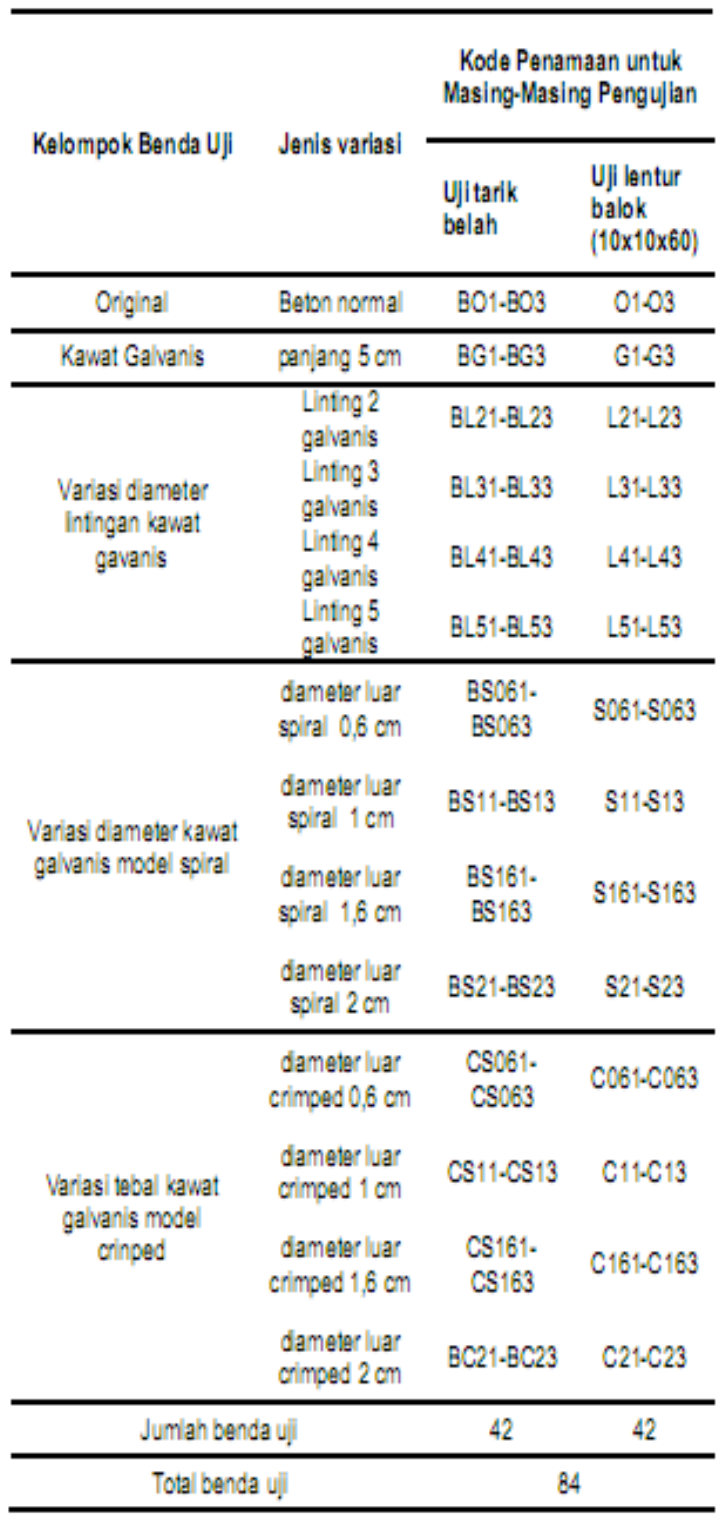

Pengujian yang dilakukan berupa uji tarik belah beton dan uji lentur balok beton dan uji lentur balok beton bertulang. Jumlah benda uji silinder sebanyak 81 buah diuji tekan umur 14 hari, 28 hari dan uji tarik belah, benda uji balok $10 \times 10 \times 60 \mathrm{~cm}^{3}$ sebanyak 27 buah diuji 
lentur, serta benda uji balok beton bertulang $15 \times 15 \times 75 \mathrm{~cm}^{3}$ yang diuji lentur.

Seluruh variasi benda uji dilakukan pengulangan sebanyak 3 benda uji. Adapun rincian benda uji dapat dilihat pada tabel 1 .

\section{Tahapan Pengujian}

Tahapan pengujian seperti pada gambar 2 .

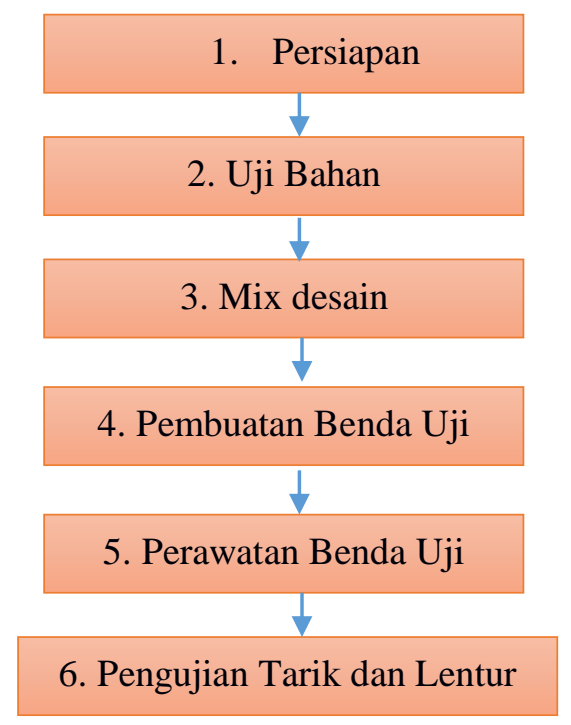

Gambar 2. Tahapan Penelitian

Penelitian ini diawali dengan persiapan alat dan bahan, kemudian dilanjutkan dengan melakukan pengujian bahan agregat halus dan agregat kasar. Tahap ke tiga adalah degan melakukan mix desain untuk beton. Setelah mix desain didapatkan maka selanjutnya dilakukan pembuatan benda uji berupa silinder dan balok beton. Benda uji yang telah jadi kemudian dirawat dalam bak perendaman beton sebelum diuji tarik dan lentur. Tahapan terakhir dari penelitian ini adalah melakukan pengujian tarik dan lentur. Pengujian tarik belh beton untuk benda uji silinder dan uji lentur untuk benda uji balok beton.

\section{HASIL PENELITIAN}

\subsection{Kuat Tarik Beton}

Dari hasil uji tarik belah beton umur 28 hari maka diperoleh nilai kuat tarik beton terbesar adalah untuk benda uji dengan penambahan galvanis model crimped yaitu $\mathrm{BC} 1$ dengan nilai kuat tarik beton sebesar $10,44 \mathrm{MPa}$ dengan peningkatan kuat tarik belah sebesar $21,68 \%$ dari beton tanpa penambahan galvanis dan meningkat sebesar $10,73 \%$ dari benda uji dengan penambahan galvanis. Hasil persentase peningkatan kuat tarik seperti pada tabel 2.

Tabel 2. Kuat Tarik Beton

\begin{tabular}{cccc}
\hline $\begin{array}{c}\text { Benda } \\
\text { Uji }\end{array}$ & $\begin{array}{c}\text { Nilai } \\
\text { Tarik } \\
\text { Belah } \\
\text { (Mpa) }\end{array}$ & $\begin{array}{c}\text { Peningkatan } \\
\text { Kuat Tarik } \\
\text { Belah Beton } \\
\text { Terhadap } \\
\text { BO } \%)\end{array}$ & $\begin{array}{c}\text { Peningkatan } \\
\text { Kuat Tarik } \\
\text { Belah Beton } \\
\text { Terhadap } \\
\text { BG } \%)\end{array}$ \\
\hline BO & 8,58 & 0 & 0 \\
\hline BG & 10,26 & 19,58 & 0 \\
\hline BL2 & 10,28 & 19,81 & 1,17 \\
\hline BL3 & 9,79 & 14,1 & $-27,99$ \\
\hline BL4 & 10,11 & 17,83 & $-8,94$ \\
\hline BL5 & 8,83 & 2,91 & $-85,14$ \\
\hline BS06 & 9,84 & 14,69 & $-24,97$ \\
\hline BS1 & 9,91 & 15,5 & $-20,84$ \\
\hline BS16 & 8,77 & 2,21 & $-88,71$ \\
\hline BS2 & 8,91 & 3,85 & $-80,34$ \\
\hline BC06 & 10,37 & 20,86 & 6,54 \\
\hline BC1 & 10,44 & 21,68 & 10,73 \\
\hline BC16 & 10,18 & 18,65 & $-4,75$ \\
\hline BC2 & 9,63 & 12,24 & $-37,49$ \\
\hline
\end{tabular}

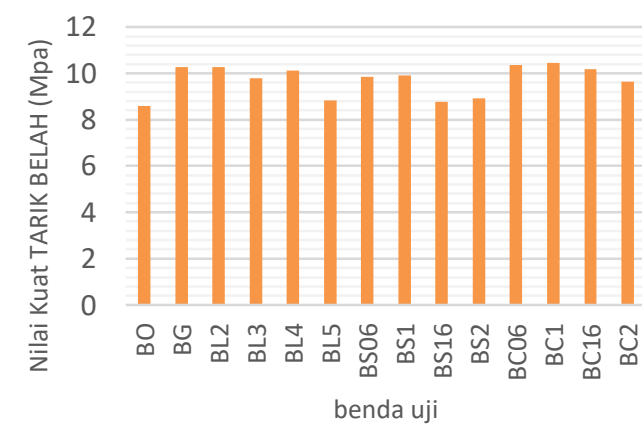

Gambar 3. Grafik Nilai Kuat Tarik Beton

Sedangkan pada gambar 3 menunjukan grafik nilai kuat tarik beton. Dapat dilihat bahwa seluruh benda uji dengan penambahan galvanis mengalami peningkatan kuat tarik belah terhadap beton normal. Ini berarti bahwa galvanis memberikan pengaruh yang baik terhadap kekuatan tarik beton. Untuk benda uji BG dengan penambahan galvanis yang dipotongpotong sepanjang $5 \mathrm{~cm}$, nilai kuat tarik belah beton sebesar 10,26 MPa dengan peningkatan kuat tekan sebesar 19,58\% terhadap BO. Untuk benda uji model linting, benda uji BL2 memiliki kuat tarik belah 
tertinggi dibandingkan benda uji model linting lainnya sebesar 10,28 MPa. Yang bearti bahwa benda uji BL2 memiliki peningkatan kuat tarik belah sebesar $19,81 \%$. Model spiral menunjukkan bahwa benda uji BS1 memiliki kuat tarik terbesar, yaitu 9,91 MPa. Pada model crimped menunjukkan bahwa benda uji BC1 memiliki kuat tarik belah terbesar, yaitu $10,44 \mathrm{MPa}$ dengan peningkatan kuat tarik belah sebesar $21,68 \%$ terhadap $\mathrm{BO}$. Dari ketiga model ini $\mathrm{BC} 1$ memiliki kuat tarik terbesar dibandingkan model lainnya.

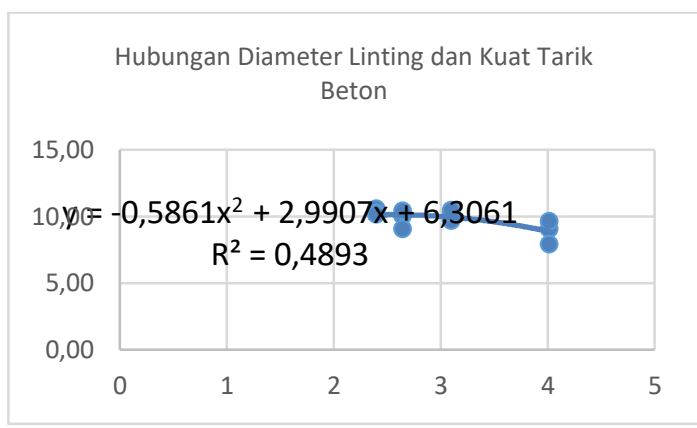

Gambar 4. Grafik Tren Kuat Tarik Benda Uji Linting

Dari grafik gambar 4, diperoleh persamaan $y=-0,5861 x^{2}+2,9907 x+$ 6,3061 dengan $R^{2}=0,489$. Sehingga didapat kuat tekan rata-rata umur 14 hari untuk tiaptiap variasi adalah sebagai berikut :

1. Benda uji L2;

$$
\begin{aligned}
y & =-0,5861 x^{2}+2,9907 x+6,3061 \\
& =10,11 \mathrm{MPa}
\end{aligned}
$$

2. Benda uji L3;

$$
\begin{aligned}
y & =-0,5861 \mathrm{x}^{2}+2,9907 \mathrm{x}+6,3061 \\
& =10,11 \mathrm{MPa}
\end{aligned}
$$

3. Benda uji L4;

$$
\begin{aligned}
y & =-0,5861 x^{2}+2,9907 x+6,3061 \\
& =9,94 \mathrm{MPa}
\end{aligned}
$$

4. Benda uji L5;

$$
\begin{aligned}
y & =-0,5861 \mathrm{x}^{2}+2,9907 \mathrm{x}+6,3061 \\
& =8,86 \mathrm{MPa}
\end{aligned}
$$

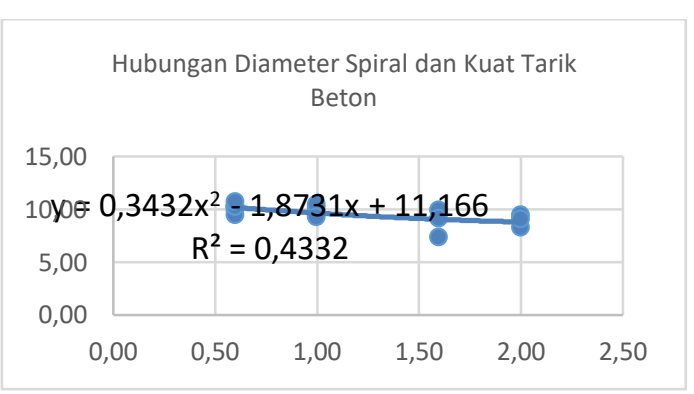

Gambar 5. Grafik Tren Kuat Tarik Benda Uji Spiral
Dari grafik pada gambar 5, diperoleh persamaan $y=0,3432 x^{2}-1,8731 x+11,166$ dengan $R^{2}=0,4332$. Sehingga didapat kuat tekan rata-rata umur 14 hari untuk tiap-tiap variasi adalah sebagai berikut :

1. Benda uji S06;

$$
\begin{aligned}
y & =0,3432 x^{2}-1,8731 x+11,166 \\
& =10,17 \mathrm{Mpa}
\end{aligned}
$$

2. Benda uji S1;

$$
\begin{aligned}
y & =0,3432 x^{2}-1,8731 x+11,166 \\
& =9,64 \mathrm{MPa}
\end{aligned}
$$

3. Benda uji S16;

$$
\begin{aligned}
y & =0,3432 x^{2}-1,8731 x+11,166 \\
& =9,05 \mathrm{MPa}
\end{aligned}
$$

4. Benda uji S2;

$$
\begin{aligned}
y & =0,3432 x^{2}-1,8731 x+11,166 \\
& =8,79 \mathrm{Mpa}
\end{aligned}
$$

Hubungan Diameter Crimped dan Kuat Tarik Belah Beton

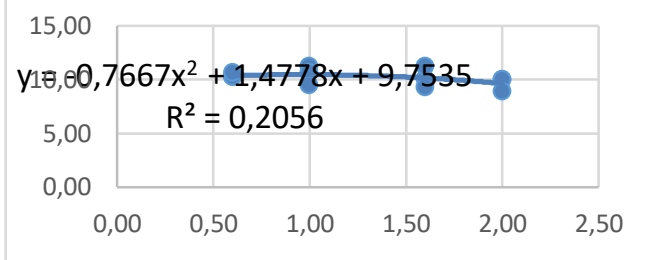

Gambar 6. Grafik Tren Kuat Tarik Belah

Benda Uji Crimped Umur 28 Hari

Dari grafik gambar 6, diperoleh persamaan $y=-0,7667 x^{2}+1,4778 x+$ 9,7535 dengan $R^{2}=0,2056$. Sehingga didapat kuat tekan rata-rata umur 14 hari untuk tiap-tiap variasi adalah sebagai berikut

1. Benda uji S06;

$$
\begin{aligned}
y & =-0,7667 x^{2}+1,4778 x+9,7535 \\
& =10,36 \mathrm{MPa}
\end{aligned}
$$

2. Benda uji S1

$$
\begin{aligned}
y & =-0,7667 x^{2}+1,4778 x+9,7535 \\
& =10,46 \mathrm{MPa}
\end{aligned}
$$

3. Benda uji S16;

$$
\begin{aligned}
y & =-0,7667 x^{2}+1,4778 x+9,7535 \\
& =10,16 \mathrm{MPa}
\end{aligned}
$$

4. Benda uji S2;

$$
\begin{aligned}
y & =-0,7667 x^{2}+1,4778 x+9,7535 \\
& =9,64 \mathrm{MPa}
\end{aligned}
$$

\section{Kuat Lentur}

Dari hasil uji lentur balok beton, diperoleh nilai kuat lentur balok beton terbesar adalah untuk benda uji dengan penambahan galvanis model linting yaitu L5 dengan nilai kuat lentur balok sebesar 7,03 MPa dengan peningkatan kuat lentur sebesar $77,53 \%$ dari beton tanpa penambahan galvanis. 
Tabel 3. Kuat Lentur Beton

\begin{tabular}{cccc}
\hline $\begin{array}{c}\text { Benda } \\
\text { Uji }\end{array}$ & $\begin{array}{c}\text { Nilai Uji } \\
\text { Lentur } \\
(\mathrm{MPa})\end{array}$ & $\begin{array}{c}\text { Peningkatan } \\
\text { Lentur Balok } \\
\text { Beton } \\
\text { Terhadap O } \\
(\%)\end{array}$ & $\begin{array}{c}\text { Peningkatan } \\
\text { Lentur Balok } \\
\text { Beton } \\
\text { Terhadap G } \\
(\%)\end{array}$ \\
\hline O & 3,96 & 0 & 0 \\
\hline G & 2,92 & $-26,26$ & 0 \\
\hline L2 & 4,18 & 5,56 & 43,15 \\
\hline L3 & 6,41 & 61,87 & 119,52 \\
\hline L4 & 2,01 & $-49,24$ & $-31,16$ \\
\hline L5 & 7,03 & 77,53 & 140,75 \\
\hline S06 & 2,84 & $-28,28$ & $-2,74$ \\
\hline S1 & 3,38 & $-14,65$ & 15,75 \\
\hline S16 & 6,18 & 56,06 & 111,64 \\
\hline S2 & 4,51 & 13,89 & 54,45 \\
\hline C06 & 5,41 & 36,62 & 85,27 \\
\hline C1 & 3,6 & $-9,09$ & 23,29 \\
\hline C16 & 2,38 & $-39,9$ & $-18,49$ \\
\hline C2 & 4,7 & 18,69 & 60,96 \\
\hline
\end{tabular}

Sedangkan pada gambar 7 adalah grafik nilai kuat lentur balok beton. Dari grafik tersebut terdapat 14 benda uji dengan nilai momentum tertinggi pada $\mathrm{L} 5$ dan terendah adalah L4.

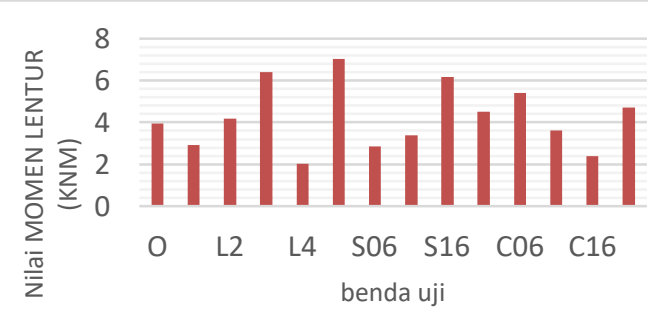

Gambar 7. Grafik Nilai Kuat Lentur Balok Beton

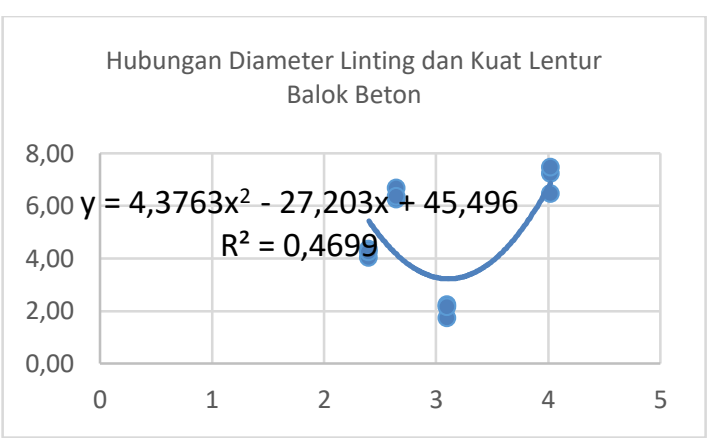

Gambar 8. Grafik Tren Kuat Lentur Balok Model Linting
Dari grafik pada gambar 8, diperoleh persamaan $y=4,3763 x^{2}-27,203 x+45,496$ dengan $R^{2}=0,4699$. Sehingga didapat kuat tekan rata-rata umur 14 hari untuk tiap-tiap variasi adalah sebagai berikut :

1. Benda uji L2;

$$
\begin{aligned}
y & =4,3763 x^{2}-27,203 x+45,496 \\
& =5,42 \mathrm{MPa}
\end{aligned}
$$

2. Benda uji L3;

$$
\begin{aligned}
y & =4,3763 x^{2}-27,203 x+45,496 \\
& =4,14 \mathrm{MPa}
\end{aligned}
$$

3. Benda uji L4;

$$
\begin{aligned}
y & =4,3763 x^{2}-27,203 x+45,496 \\
& =3,22 \mathrm{MPa}
\end{aligned}
$$

4. Benda uji L5;

$$
\begin{aligned}
y & =4,3763 x^{2}-27,203 x+45,496 \\
& =6,86 \mathrm{Mpa}
\end{aligned}
$$

Hubungan Diameter Spiral dan Kuat Lentur Balok Beton

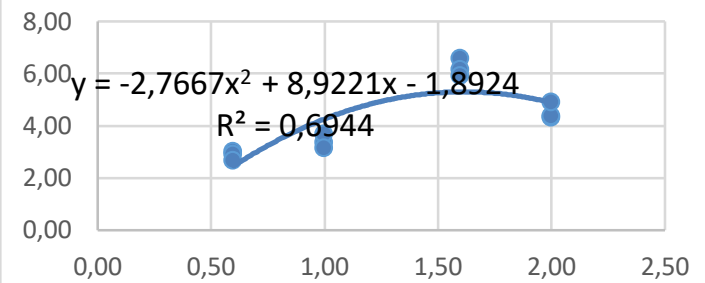

Gambar 9. Grafik Tren Kuat Lentur Balok Model Spiral

Dari grafik gambar 9 , diperoleh persamaan $y=-2,7667 x^{2}+8,9221 x-1,8924$ dengan $R^{2}=0,6944$. Sehingga didapat kuat lentur untuk tiap-tiap variasi adalah sebagai berikut:

1. Benda uji S06;

$$
\begin{aligned}
y & =-2,7667 x^{2}+8,9221 x-1,8924 \\
& =2,46 \mathrm{MPa}
\end{aligned}
$$

2. Benda uji S1;

$$
\begin{aligned}
y & =-2,7667 x^{2}+8,9221 x-1,8924 \\
& =4,26 \mathrm{MPa}
\end{aligned}
$$

3. Benda uji S16

$$
\begin{aligned}
y & =-2,7667 x^{2}+8,9221 x-1,8924 \\
& =5,30 \mathrm{MPa}
\end{aligned}
$$

4. Benda uji S2;

$$
\begin{aligned}
y & =-2,7667 x^{2}+8,9221 x-1,8924 \\
& =4,89 \mathrm{MPa}
\end{aligned}
$$

Hubungan Diameter Crimped dan Kuat Lentur Balok Beton

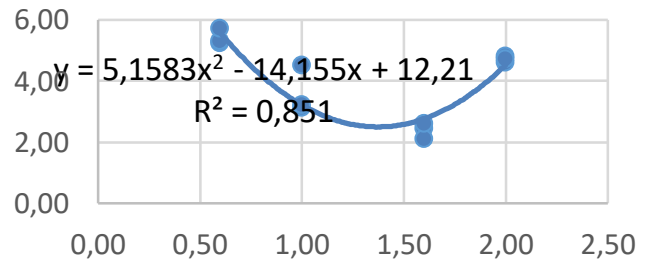

Gambar 10. Grafik Tren Kuat Lentur Balok Crimped 
Dari grafik pada gambar 10, diperoleh persamaan $y=5,1583 x^{2}-14,155 x+12,21$ dengan $R^{2}=0,851$. Sehingga didapat kuat lentur untuk tiap-tiap variasi adalah sebagai berikut :

1. Benda uji C06;

$$
\begin{aligned}
y & =5,1583 x^{2}-14,155 x+12,21 \\
& =5,57 \mathrm{MPa}
\end{aligned}
$$

2. Benda uji $\mathrm{C} 1$;

$$
\begin{aligned}
y & =5,1583 x^{2}-14,155 x+12,21 \\
& =3,21 \mathrm{MPa}
\end{aligned}
$$

3. Benda uji C16;

$$
\begin{aligned}
y & =5,1583 x^{2}-14,155 x+12,21 \\
& =2,77 \mathrm{MPa}
\end{aligned}
$$

4. Benda uji C2;

$$
\begin{aligned}
y & =5,1583 x^{2}-14,155 x+12,21 \\
& =4,53 \mathrm{MPa}
\end{aligned}
$$

\section{KESIMPULAN DAN SARAN}

\section{Kesimpulan}

Kesimpulan dari penelitian ini adalah:

1. Nilai kuat tarik belah rata-rata beton umur adalah 8,58 MPa; 10,26 MPa; 10,28 MPa; 9,79 MPa; 10,11 MPa; 8,83 $\mathrm{MPa}$; 9,84 MPa; 9,91 MPa; 8,77 MPa, 8,91 MPa; 10,37 MPa; 10,44 MPa; 10,18 $\mathrm{MPa}$ dan 9,63 $\mathrm{MPa}$ masing-masing untuk benda uji BO, BG, BL2, BL3, BL4, $\mathrm{BL5}$, BS06, BS1, BS16, BS2, BC06, $\mathrm{BC} 1, \mathrm{BC} 16$, dan $\mathrm{BC} 2$.

2. Nilai kuat lentur rata-rata beton adalah 3,96 MPa; 2,92 MPa; 4,18 MPa; 6,41 $\mathrm{MPa}$; 2,01 MPa; 7,03 MPa; 2,84 MPa; 3,38 MPa; 6,18 MPa; 4,51 MPa; 5,41 $\mathrm{MPa} ; 3,60 \mathrm{MPa} ; 2,38 \mathrm{MPa}$ dan 4,70 $\mathrm{MPa}$ untuk masing-masing untuk benda uji O, G, L2, L3, L4, L5, S06, S1, S16, S2, C06, C1, C16, dan C2.

\section{Saran}

Diperlukan adanya penelitian lebih lanjut tentang persentase dari kawat galvanis dalam campuran beton.

\section{DAFTAR PUSTAKA}

[1] Abdul Azis. "Studi Tarik Belah Beton dengan Penambahan Dramix Steel Fiber", Naskah Publikasi, (2016): 1-11

[2] Ahmad Saifudin. "Pengaruh Dosis, Aspek Rasio, dan Distribusi Serat Terhadap Kuat Lentur dan Kuat Tarik Belah Beton Berserat Baja", e-Jurnal Matriks Teknik Sipil (Juni, 2015): 369376
[1] Basuki. "Pemanfaatan Kawat Galvanis Dipasang Secara menyilang pada Tulangan Begel Balok Beton untuk Meningkatkan Kuat Lentur Balok Beton Bertulang", Simposium Nasional RAFI XII (2013) FT UMS: S28-S36

[2] Eddy Purwanto. "Studi Kuat Lentur Beton Ringan Berserat Kawat Galvanis", Jurnal Rekayasa, (2011): vol 11 No.3 